ISSN: 2469-4142

\title{
Journal of Nutritional Biology
}

\section{Research Article}

\section{Calcium-Dependent Eukaryotic Initiation Factor 2a Phosphatase Complexed with Calcineurin Restores Control to Anterior Piriform Cortex Neural Circuitry after Activation by Essential Amino acid Deficiency}

\author{
Gietzen DW ${ }^{1 *}$, Ross-Inta $\mathrm{CM}^{1,2}$, Rudell JB${ }^{1,3}$, Hao $\mathbf{S}^{1,4}$ and Donovan $\mathbf{M}^{1,5}$
}

'Department of Anatomy, Physiology and Cell Biology, School of Veterinary Medicine, University of California, Davis, One Shields Avenue, Davis, CA 95616, USA

${ }^{2}$ Comparative Pathology, School of Veterinary Medicine, University of California, Davis, One Shields Avenue, Davis, CA 95616, USA

${ }^{3}$ Napa Community College, Napa CA, USA

${ }^{4}$ Ajinomoto North America, Inc, 400 Kelby Street, Fort Lee NJ 07024, USA

${ }^{5}$ Federal Occupational Health, Bethesda MD, USA

Received: Sept 13, 2015; Accepted: Dec 24, 2015; Published: Jan 03, 2016

\begin{abstract}
Essential (dietary-indispensable) amino acids (IAA)s are vital precursors for protein synthesis; they cannot be synthesized in metazoans but must be obtained from food to survive. In sensing a reduction of an IAA, the mammalian anterior piriform cortex (APC) is rapidly activated. The initial behavioral response is an abrupt end to an IAA deficient meal about 20 min after meal onset. IAA depletion in the APC activates the conserved eukaryotic initiation factor $2 a$ (elF2a) kinase, GCN2, via uncharged tRNA. GCN2 kinase activity increases phosphorylation of elF2a (P-elF2a), which blocks global protein synthesis. The result is that APC inhibitory elements with short half-lives cannot be replaced. Without their inhibition in this highly sensitive brain area, activation of the glutamatergic output cells ensues. Following APC activation, P-elF2a must be reduced to release the blockade on protein synthesis and allow recovery of inhibition in the circuit. This completes the homeostatic response, restoring control in the APC. A role for calcium $\left(\mathrm{Ca}^{2+}\right)$ in regulating P-elF2a was explored here using $\mathrm{Ca}^{2+}$ blockers, immunoblotting and electrophysiology in APC brain slices. The responses to IAA depletion in the APC were $\mathrm{Ca}^{2+}$ dependent, showing a role for $\mathrm{Ca}^{2+}$ in the system. Yet, the kinase activity of GCN2 was unaffected by intracellular $\mathrm{Ca}^{2+}$ chelation. Thus, control must be accomplished by phosphatase activity. We suggest that regulation of P-elF2a, and neuronal stability in the APC, require the activity of protein phosphatase1, a Ca ${ }^{2+}$-dependent subunit of the phosphatase acting on P-elF2a. This implicates the Ca2+/ calmodulin-dependent calcineurin (Protein Phosphatase 2B/PP2B) as acting with the constitutive repressor of elF2 phosphorylation (PPP1R15B/CReP) after GCN2 activation in the brain.
\end{abstract}

*Correspondence: Gietzen DW, Department of Anatomy, Physiology and Cell Biology, School of Veterinary Medicine, One Shields Ave, Davis CA 95616, USA, Tel: +1 530-756-9420; Fax: +1 530-752-7690; E-mail: dwgietzen@ucdavis.edu 
Keywords: CReP; GCN2; Brain slice; Paleocortex; P-elF2a; Essential amino acid deficiency

Abbreviations: APC: Anterior Piriform Cortex; CaN: Calcineurin (Protein phosphatase 2B[PP2B]); CReP: Constitutive Repressor of elF2a Phosphorylation/ PPP1R15b; Dev: IAA devoid medium; elF2a; a-subunit of the Eukaryotic Initiation Factor 2; EPSP: Excitatory Postsynaptic Potential; GCN2: General Control Nonderepressible 2 kinase (EIF2AK4); IAA: Indispensable Amino Acid; KCC2: Neuronal Potassium Chloride Cotransporter; LOT: Lateral Olfactory Tract; Norm U: Normalized Volume Density Units; P-: Phosphorylated; PEK/PERK: Pancreatic elF-2alpha Kinase (EIF2AK3); PP1: Protein Phosphatase1; PPP1R15: PP1's Regulatory Subunit 15

\section{Introduction}

Essential (indispensable) amino acids (IAA) are the critical precursors for protein synthesis that must be obtained from food; their deprivation is first sensed in the highly excitable anterior piriform cortex (APC), a paleocortex in the vertebrate brain $[1,2]$. Omnivorous mammals and birds show rapid sensing of IAA deficient food during the first meal; they reject a deficient diet within $20 \mathrm{~min}$ [3]. This adaptive behavioral response is associated with activation of neurons both in vivo [4] and in vitro [5], found in the ventro-rostral area of the APC (APCvr) [5-7]. The APCvr has few inhibitory elements, rendering it highly excitable [6]. The activated APC projects to appropriate feeding/foraging circuits in the brain, initiating the behavioral responses [8].

The first six steps of this conserved signaling mechanism are found in the APC [9], reviewed in Gietzen et al. and Anthony and Gietzen [2,10]: leading to interruption of global protein synthesis. Without protein synthesis to restore the rapidly-turning-over potassiumchloride cotransporter (KCC2) and the GABA $A_{A}$ receptor, these crucial control elements are quickly depleted [11], activating the APC circuitry. The mechanism for restoration of control to APC circuits after excitation by IAA deficiency is the final step to be revealed in this homeostatic system.

Several lines of evidence suggest that $\mathrm{Ca}^{2+}$ plays a role in the APC's responses to IAA depletion. There is increased $\mathrm{Ca}^{2+}$ in APC slices in vitro [12] upon repletion after the slices had been deprived of an IAA for 2-6 h. Phosphorylated-CaMKII (P-CaMKII), an accepted indicator both of increased intracellular $\mathrm{Ca}^{2+}\left[\mathrm{Ca}^{2+}\right]_{i}$ and activated calmodulin (CaM), was increased in the APC of rats 20 min after introduction of an IAA deficient diet [13]. Moreover, $\mathrm{Ca}^{2+}$ is required for sensing AAs (but not exclusively IAA) by a $\mathrm{Ca}^{2+}$ receptor [14]. Finally, the class III phosphatidylinositol 3-kinase, hVps34, which requires BAPTA-sensitive $\left[\mathrm{Ca}^{2+}\right]_{i}$ in order to activate mTOR via CaM [15], is also implicated in the APC's response to an IAA deficient food [16]. These several findings implicate $\mathrm{Ca}^{2+}$ in the APC's responses to IAA depletion, albeit in various ways.

To investigate how $\mathrm{Ca}^{2+}$ is involved in the signaling of IAA deficiency in the APC we subjected APC slices to several $\mathrm{Ca}^{2+}$-modulating treatments, in either an IAA (threonine) deficient (Dev) or a corrected (COR, i.e., control (Cont)) medium, and also studied microchip array results in APC slices from rats fed either Dev or Cont. The results are consistent with a role for a $\mathrm{Ca}^{2+}$ dependent phosphatase complex in restoring inhibitory control to the APC after activation by IAA deficiency.

\section{Materials and Methods}

\section{Animals}

Male Sprague-Dawley rats (Harlan, Livermore CA, weighing 180-250 g) were paired and housed in plastic cages in a vivarium at room temperature $\left(22^{\circ} \mathrm{C} \pm 2^{\circ} \mathrm{C}\right)$ with an inverted 12:12 dark:light cycle in an artificially illuminated $22 \pm 2^{\circ} \mathrm{C}$ laboratory. Animal care protocols followed NIH guidelines (NIH Guide for the Care and Use of Laboratory Animals) and were approved by our Institutional Animal Care and Use Committee. Fresh water and diet were freely available. A threonine basal diet (BAS), or $6 \%$ casein (each contains about $40 \%$ of the requirement for the limiting IAA) was fed for at least a week. For the in vitro studies, the tissue was taken without further dietary changes. For the gene-chip experiments, animals were fed BAS for the week prior to the experiment and then given a fresh food cup with either BAS, threonine devoid (Dev) or an IAA complete diet (corrected, COR i.e., Control, Cont) for $2 \mathrm{hr}$ prior to 
collection of the APC tissue; for details and rationale for use of these diets see Koehnle et al. [3].

Brain slices: For each slice experiment the brain was quickly removed and prepared as in Rudell et al. [5]. APC slices $(400 \mu \mathrm{m})$ were dissected as described in detail [5], and kept in aerated control medium for recovery from slicing. The most responsive area of the APC as determined previously [5,7] was included in the slices, which were bisected to provide bilateral experimental and control hemislices. The samples were switched to either Cont or Dev, with or without $\mathrm{Ca}^{2+}$ inhibitors (see below). Replacement of media required 2 min for complete mixing, determined in preliminary experiments using colored media. After the buffer was switched, the sections remained in the new buffer for an additional $3 \mathrm{~min}$. Thus, the slices were exposed to the test media for approximately $5 \mathrm{~min}$, according to the recommendation of Hou and Klann [17], and because the electrophysiological response to Dev can take as little as 6 min [5].

Western blots: Tissues were then prepared for immunoblotting: Brain tissue was homogenized in extraction buffer $(0.25 \mathrm{M}$ Tris- $\mathrm{HCl}, \mathrm{pH} 6.8 ; 2.5 \%$ sodium dodecyl sulfate [SDS]; 2 mM EDTA; 2 mM EGTA; 10\% glycerol; 5\% 2-mercaptoethanol) with protease and phosphatase inhibitor cocktails I and II diluted at 1:100 (Sigma, St. Louis, MO). The homogenate was heated for 10 minutes at $100^{\circ} \mathrm{C}$ and centrifuged at $3,000 \mathrm{rpm}$ for 10 minutes, and the supernatant was stored at $-80^{\circ} \mathrm{C}$ until analyzed. Protein levels in the brain samples were analyzed via the Bio-Rad (Hercules, CA) DC Protein Assay, a modification of the Lowry assay. Colorimetric absorbencies were read on a Multiskan Ascent 96-well platereader(LabsystemsOy,Helsinki,Finland).Samples were diluted $1: 2$ or $1: 4$ in an SDS reducing buffer and electrophoresed at $200 \mathrm{~V}$ for approximately 50 minutes in Invitrogen (Carlsbad, CA) 10\% BisTris gels. Volumes of samples added to wells were adjusted so that equal amounts of protein were added to each well. Proteins were transferred to a polyvinylidene difluoride (PVDF) membrane. PVDF membranes were immunoblotted using the following antibodies: phosphorylated elF2a (rabbit polyclonal IgG (Phospho-elF2a [Ser51], Cell Signaling Technology, Beverly, MA) diluted 1:1000), phosphorylated CaMKII (rabbit polyclonal IgG [Anti-
ACTIVE CaM KII pT286, Promega, Madison, WI] diluted 1:2000), phosphorylated pancreatic elF2alpha kinase PEK/PERK (EIF2AK3) (Thr 981, Santa Cruz Biotechnology, Santa Cruz, CA, diluted 1:200). Antibodies were diluted as listed above into $5 \%$ nonfat dry milk dissolved in TBS-T (Trisbuffered saline with $0.1 \%$ Tween-20, pH 7.5) for 1 hour at $24^{\circ} \mathrm{C}$ and then overnight at $4^{\circ} \mathrm{C}$. Biotinylated protein standards (Cell Signaling) were diluted according to the manufacturer's protocol and visualized with horseradish peroxidase (HRP)-conjugated anti-biotin antibody (Cell Signaling) diluted 1:2,000. The secondary antibodies, an antirabbit IgG conjugated with HRP (Cell Signaling) or an anti-mouse IgG conjugated with HRP (Cell Signaling) were diluted 1:2,000. The HRPconjugated secondary antibody and the HRP-conjugated anti-biotin antibody were mixed into $10 \mathrm{ml}$ of $5 \%$ milk (w/v) in TBS-T and incubated for 1 hour with the PVDF membrane. The membrane was then washed three times with TBS-T and incubated with the chemiluminescent reagent $(0.5 \mathrm{ml}$ of 20 times LumiGLO [Cell Signaling], $0.5 \mathrm{ml}$ of 20 times peroxide [Cell Signaling], into $9.0 \mathrm{ml}$ of double-distilled $\mathrm{H}_{2} \mathrm{O}$ ) for 1 minute at $24^{\circ} \mathrm{C}$. Membranes were placed on Kodak X-OMAT AR film (Eastman Kodak, Rochester, NY) for 15 seconds to 30 minutes. Quantitative analysis of phosphoproteins in the digitized Western blot images was done using ImageQuant5.1 (Molecular Dynamics, Piscataway, NJ). Western blot bands were evaluated for volume density; this was the integrated intensity of all pixels excluding the background. After scanning for the protein of interest, the same blots were stained with Coomassie Blue, re-scanned and protein levels were determined for each band, again using ImageQuant.

For electrophysiology: After APC slice dissection as described in Rudell et al. [5], excitatory post synaptic field potentials (EPSP) were evoked by stimulating either the lateral olfactory tract (LOT) or layer III and recorded from layer III of the APC using standard electrophysiological techniques. See Rudell et al. [5] for details and examples of the electrophysiological responses. Experimental media were Cont or Dev with and without inhibitors as in the Western blot studies described above.

Inhibitors: Calcium chelators were: BAPTA-AM (30 $\mu M)$, EGTA (4 mM), and EGTA-AM $(30 \mu M)$; inhibitors 
were:ryanodine ( $0.1,1$ or $5 \mu \mathrm{M}, 9,12$ de-hydro ryanodine) and Ruthenium Red, a mitochondrial uncoupler that is also a nonselective ryanodine receptor blocker $(10 \mu \mathrm{M})$, from Calbiochem, San Diego CA. Inhibitors from Sigma were: the L-type $\mathrm{Ca}^{2+}$ channel blocker, nifedipine (15 $\mu \mathrm{M}, \quad$ 1,4-Dihydro-2,6-dimethyl-4-(2-nitrophenyl)-3,5pyridinedicarboxylic acid dimethyl ester), thapsigargin, a selective inhibitor of the sarco/endoplasmic reticulum calcium ATPase, $(0.1,0.3$ or $10 \mu \mathrm{M})$, and FCCP (10 $\mathrm{nM})$. a selective mitochondrial uncoupler [18].

Data analysis: Data for the phosphoprotein of interest were normalized to the protein level determined by Coomassie Blue staining in the same band as described above and are reported as normalized density units (NormU). Because increased P-elF2a indicating the response of GCN2 to IAA deprivation is well established [19] as seen in the APCvr area [7], slices that failed the positive control criteria: Dev>Cont for P-elF2a, indicating misplaced dissections, were excluded. Data sets were analyzed by 2-way ANOVA using the anatomical location of the slice (in $\mathrm{mm}$ anterior to Bregma) and the contents of the media as independent variables and the normalized phosphoprotein units (Norm $U$ ) as the dependent variable. After a significant ANOVA, differences among means were determined by the Fischer's LSD test. For comparing 2 samples, we used the Student's $t$ test. Where control and test samples were bilateral sections from the same slice, a paired $t$ test was used.

For electrophysiological data, we report either EPSP amplitude $(\mathrm{mV})$, or normalized responses, the ratio, EPSP amplitude in Dev to the baseline in Cont, Mean \pm standard error. The EPSP response to IAA depletion \pm inhibitors was compared with one way ANOVA. Differences between slopes were determined by a $Z$ score.

Microchip analysis: The tissues were processed as reported previously [20] and hybridized to the Affymetrix Rat Neurobiology U34 chip. This microarray contains sequences from approximately 1300 known genes and will reliably detect at least a 2-fold difference in mRNA expression. Results were re-analyzed using the April 2015 revision of the Affymetrix annotation tables and subjected to Gene Ontology analysis (GO
Ontology database, released August 6, 2015). For the GO analysis, the Bonferroni correction for multiple testing was used. Significance was assumed at $P<0.05$.

\section{Results}

\section{Extracellular $\mathrm{Ca}^{2+}$}

P-elF2a: After 5 min in media containing 4 mM EGTA

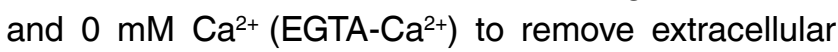
calcium $\left[\mathrm{Ca}^{2+}\right]_{0}$ from the Dev slice medium, P-elF2a was slightly, but non-significantly lower relative to Dev alone, while P-elF2 $a$ in both Dev and Dev+EGTA-Ca ${ }^{2+}$ remained higher than in Cont (media effect, $\mathrm{F}_{2,18}=3.74$, $\mathrm{P}=0.044$ ), Figure $1 \mathrm{a}$ and $\mathrm{b}$.

P-CaMKII: There was no difference due to slice location within the APC. Removing $\left[\mathrm{Ca}^{2+}\right]_{0}$ from the Dev medium reduced $\mathrm{P}-\mathrm{CaMKII}$ to the control level $\left(F_{8,27}=3.22, P=0.011 ;\right.$ Figure $1 a$ and $b$.

Electrophysiology: When $\left[\mathrm{Ca}^{2+}\right]_{\circ}$ was removed from the medium, the EPSP was abolished, showing the well known requirement for $\mathrm{Ca}^{2+}$ in synaptic transmission, Figure 1c. Nifedipine: When L-type $\mathrm{Ca}^{2+}$ channels, which allow $\left[\mathrm{Ca}^{2+}\right]_{\circ}$ entry into the cell, were blocked by nifedipine $(15 \mu \mathrm{M})$, the EPSP response to Dev was blunted for about 40 min (more than enough time for the behavioral response at $20 \mathrm{~min}$, see above), Figure 1d. Clearly, both P-CaMKII, and increased amplitude of the EPSP in the Dev medium (showing activation of the APC), require $\left[\mathrm{Ca}^{2+}\right]_{0}$. The lack of significance for P-elF2a suggests that extracellular $\left[\mathrm{Ca}^{2+}\right]_{0}$ is not required. Therefore, we studied intracellular calcium $\left[\mathrm{Ca}^{2+}\right]_{\mathrm{i} .}$ using BAPTA/AM as in Gulati et al. [15].

Intracellular $\mathrm{Ca}^{2+}$ : The membrane-permeable form of BAPTA, BAPTA/AM (BAP), is an intracellular $\mathrm{Ca}^{2+}$ chelator acting on fast $\left[\mathrm{Ca}^{2+}\right]_{i}$ events [21]. BAP was used at 10 or $30 \mu \mathrm{M}$; results were consistent over 10 studies.

P-elF2a: In 2 trials BAP $(10 \mu \mathrm{M})$ reduced elF2a phosphorylation in both Dev and Cont media (effect of $\left.\mathrm{BAP}, \mathrm{F}_{3,6=} 5.04, \mathrm{P}=0.04\right)$. Thereafter we used BAP at $30 \mu \mathrm{M}$. There were no differences between the results at these doses, so the data were combined. Overall, the effect 

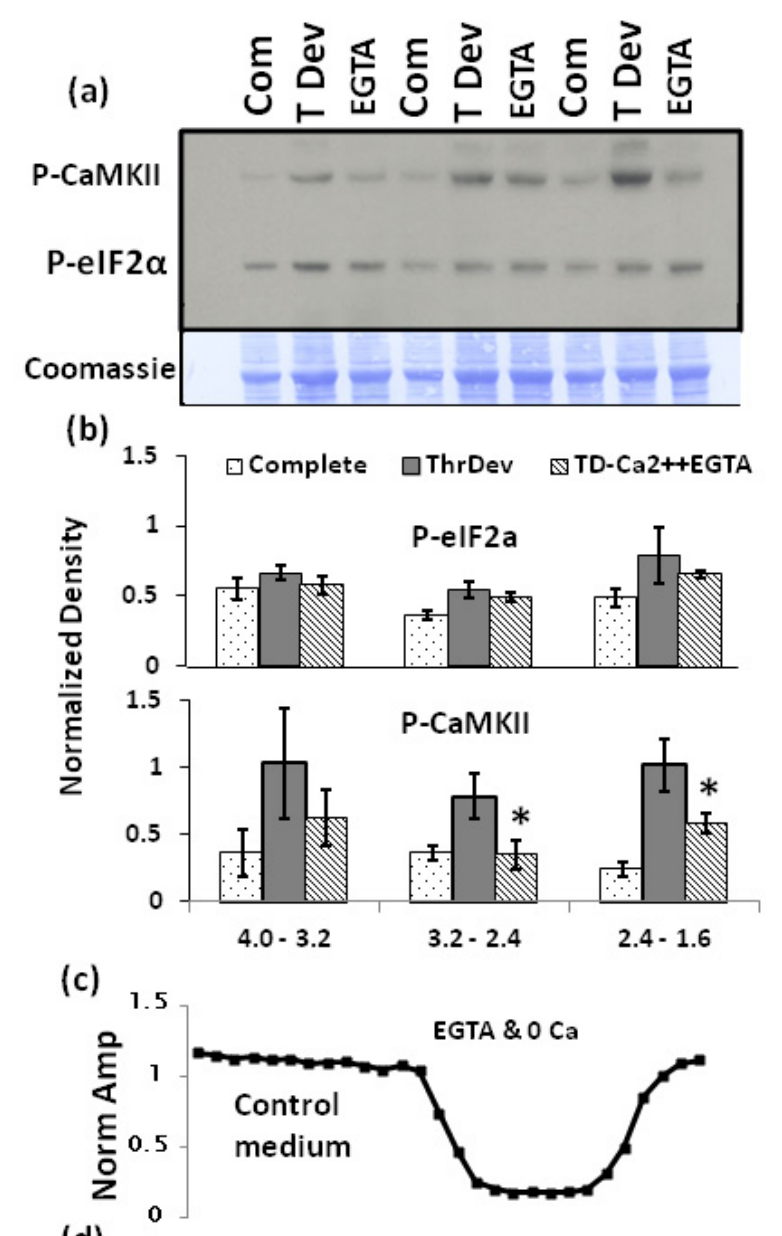

(d)

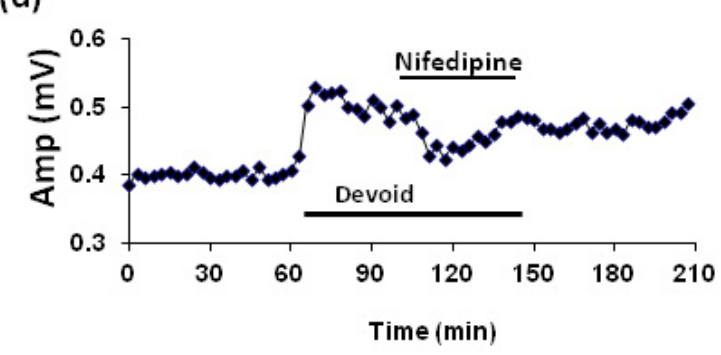

Figure 1: Effects of EGTA on P-elF2a and P-CaMKII. (a): Segments of western blots for P-CaMKII (top), P-elF2a (middle) and Coomassie-stained protein in the same blots (bottom). Treatments: Cont, TDev or Dev/EGTA-Ca ${ }^{2+}$ (EGTA), are indicated across the top. Slice locations in $\mathrm{mm}$ anterior to Bregma are shown below the bar graphs. (b): Normalized density units (Norm U) for P-elF2 $a$ and P-CaMKII, means \pm SE. Stars "*" indicate significance at $P<0.05$. (c): Normalized amplitude (Norm Amp) of the EPSP in APC layer III. Media changes indicated above the timeline indicate times of exposure to the slice. $(\mathrm{d})$ : Amplitude $(\mathrm{mV})$ of EPSP over time, with additions to the media as indicated.

of slice location was significant $\left(\mathrm{F}_{2,132}=9.75, \mathrm{P}=0.0001\right)$, Figure 2a. BAP reduced P-elF2a in both Cont and Dev (for the effect of reduced $\left[\mathrm{Ca}^{2+}\right]_{i}: \mathrm{F}_{3,132}=6.46: \mathrm{P}=0.0004$, indicated by * in Figure 2b, compare the black bars for
BAPTA vs lighter bars for Vehicle). Importantly, BAP failed to block the effect of IAA depletion. The increases due to Dev, with or without BAP, were highly significant, $\mathrm{P}<0.005$. In duplicate studies with all 4 groups run 


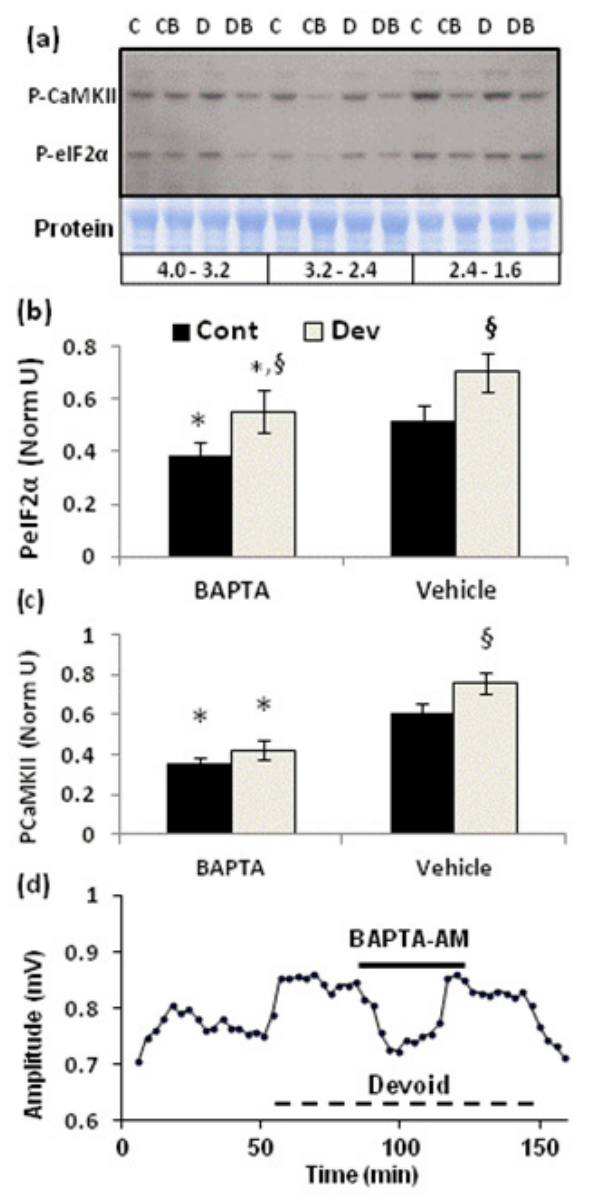

Figure 2: Effects of BAPTA/AM (BAP). Lanes in the western blot (a) are indicated across the top as C: Cont, CB: Cont+BAP, D: Dev, DB: Dev+BAP. "Protein" is the Coomassie Blue stained band, as in Figure 1. Figure 2(b): P-elF2a in samples as described in Figure 1(b). Here, control (Cont, dark bars) and threonine devoid medium (Dev, grey bars); treatments, BAPTA or Vehicle, are given on the $\mathrm{X}$ axis. Figure 2(c): P-CaMKII, as for Figure 2(b). Stars "*” indicate significance at $\mathrm{P}<0.05$ for BAP effect. The symbol " $\S$ " indicates significance of IAA depletion in the Dev slices, showing intact GCN2 activity. (d): EPSP in APC, see text for sequence of responses.

simultaneously, P-elF2a was increased in both BAP and Vehicle conditions, indicating similar GCN2 kinase activity, unaffected by BAP. The increases in P-elF2a the Dev medium, in vehicle or BAP were: $1.15 \pm 0.06$ or $1.35 \pm 0.12$, respectively; there was no difference, $\mathrm{P}=\mathrm{NS}$; for the intact GCN2 kinase (Dev) effect see the "§" over the Dev bars in Figure 2b.

P-CAMKII: Both medium and slice location showed significant effects: ( medium $\mathrm{F}_{3,132}=13.2, \mathrm{P}<0.001$; slice location $\left.F_{2,132}=8.25, P=0.0004\right)$, Figure 2c. Here the effects of BAP $\left(^{*}\right)$ reduced P-CaMKII in both Dev and Cont media, and blocked the Dev effect, which was only seen in the vehicle group (§).

Electrophysiology: The EPSP in APC slices mirrored the P-elF2a blot results, Figure $2 \mathrm{~d}$. When the medium was changed from Cont to Dev (after approx. $50 \mathrm{~min}$ of baseline recording) the rapid increase in EPSP amplitude is seen clearly, as expected [5]. When BAP $(30 \mu \mathrm{M})$ was added to the Dev medium, the EPSP amplitude was reduced to Cont levels. Similar results in 7 studies showed an average increase due to Dev of $10 \pm 2 \%$, paired $t, \mathrm{P}=0.02$. Addition of BAP to the medium reduced the EPSP to $-4 \pm 4 \%$, i.e., returned to baseline. There was no consistent effect seen when 

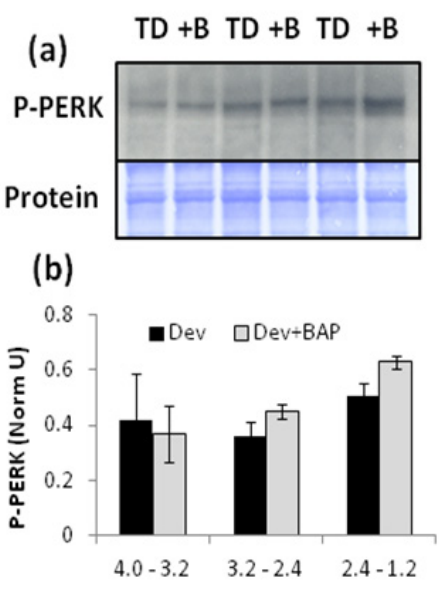

Figure 3: Means and SE for (a) Effect of BAP on Norm U for P-PERK in slices prepared as in Figures 1 and 2. Conditions are as in Figures 1 and 2, again Protein is shown as the Coomassie stain, here the control medium was Dev; there were no significant differences.

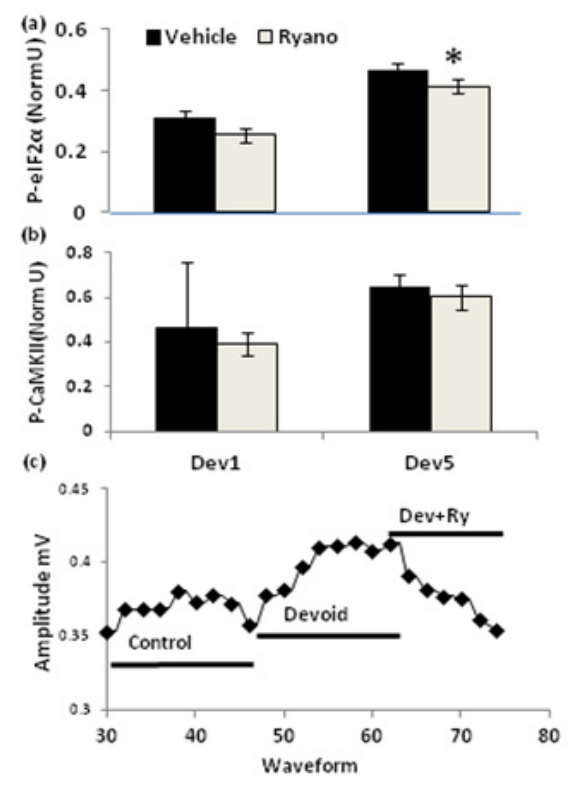

Figure 4: Effects of ryanodine (Ryano, Ry). Dev1 (1 $\mu \mathrm{M}$ Ryano in Dev) or Dev 5 (5 $\mu \mathrm{M}$ Ryano in Dev) on (a), P-elF2 $a$ and (b), P-CaMKII, Norm $U$ as described for Figure 1. The star "*” indicates $P<0.05, N=5$ studies. (c): EPSP amplitudes (mV) in APC slices bathed in Control, Devoid or Dev+Ry (ryanodine, $5 \mu \mathrm{M}$ ). Timing and durations of media applications are indicated above waveform numbers on the $\mathrm{X}$ axis.

BAP was added to the Cont medium for slice recording (data not shown).

EGTA/AM blocks slow intracellular $\mathrm{Ca}^{2+}$ events, but here it had no effect on the increased amplitude of the EPSP response to the Dev medium (ratio Dev+vehicle:Cont: $1.11 \pm 0.13$ vs Dev+EGTA/AM:Cont:
$1.12 \pm 0.18, \mathrm{NS})$. This shows that slow $\mathrm{Ca}^{2+}$ events are not involved in the responses studied here, and provides an important control to show that the results with BAPTA/AM were not due to the AM moiety.

Other elF2 kinases: There are four elF2a kinases (EIF2AK1-4), including GCN2 (EIF2AK4) [19]. PKR 
(EIF2AK2) has been shown to be dispensable for sensing IAA deficiency [22] and HRI (EIF2AK1) has not been reported in brain tissue; these 2 were not tested here. To learn whether BAP was reducing P-elF2a via an effect on elF2a activated by EIF2AK3/PEK/ PERK in the APC, we measured P-PERK in Dev \pm BAP. Rather than a decrease, as we saw with P-elF2a in the Dev+BAP medium, there was a small increase in P-PERK (Control: $0.36 \pm 0.06$ vs Dev+BAP: $0.46 \pm$ $0.08, \mathrm{P}=0.055$, NS via paired $t$ test), Figure 3. Clearly BAP did not reduce the expression of P-PERK. Thus the effects of BAP in lowering P-elF2a were not due either to kinase or phosphatase activity involving PEK/ PERK.

Thapsigargin is known to cause ER stress and activate PEK/PERK [23]. To provide a further test for PEK/PERK we used thapsigargin $(10 \mu \mathrm{M})$ in Dev. There were no changes in either P-elF2a or P-CaMKII expression with thapsigargin $\left(F_{1,18}=0.491, P=N S\right.$ and $F_{5,17}=0.253$, $\mathrm{P}=\mathrm{NS}$ ) at any of the slice levels. Similarly, the EPSP study with thapsigargin $(0.1 \mu \mathrm{M})$, the response to Dev medium was unaffected.

Sources of $\left[\mathrm{Ca}^{2+}\right]_{\mathrm{i}}:$ Ryanodine receptors:, 9,21-Dehydro-Ryanodine blocks $\mathrm{Ca}^{2+}$ induced-Ca ${ }^{2+}$ release from the endoplasmic reticulum through its eponymous receptors (RyRs). Ryanodine (1 $\mu \mathrm{M})$ showed a directional decrease of P-elF2a $\left(F_{1,18}=0.39\right.$, $\mathrm{P}=\mathrm{NS}$ ), and at $5 \mu \mathrm{M}$ ryanodine provided a significant blockade of the Dev-induced increase in P-elF2a expression $\left(F_{1,8}=8.326, P=0.02\right)$, Figure $4 a$. There was no effect of ryanodine in the Cont medium $\left(F_{1,12}=0.13, P=N S\right)$. $P$-CaMKII: In contrast to the results for P-elF2a, there was a directional decrease, but not a significant effect, of ryanodine on P-CaMKII $(1 \mu \mathrm{M}$ : $F_{1,6}=1.76, P=N S$ or $5 \mu M: F_{1,12}=0.37, P=N S$, or Cont: $F_{1,18}=2.46, P=N S$ ), Figure $4 b$. This is again consistent with intracellular activity of P-elF2a, as appropriate for a cytoplasmic protein.

Electrophysiology: Ryanodine $(50 \mu \mathrm{M})$ in the Dev slice medium caused a clear reduction of the EPSP amplitude to Cont levels, Figure 4c.

Insp ${ }_{3}$ channel: U73122, a mixed agonist of PLC $[24,25]$ was used to probe the $\operatorname{InsP}_{3} \mathrm{Ca}^{2+}$-release channel on the ER (10 or $20 \mu \mathrm{M})$. In each of 4 studies there was an early decline in the EPSP $\left(R^{2}=0.82\right.$, slope $=-0.181)$, followed by a steep increase $\left(R^{2}=0.75\right.$, slope=0.0165; $Z>3.5, P<0.01$ ), consistent with early inhibitory activity followed by stimulation. This is consistent with action as a mixed antagonist/agonist of PLC, but will require further study.

Mitochondria: The blockers, Ruthenium red and FCCP, both failed to have any effect; in normalized units for Ruthenium red: P-elF2a (Dev:0.67 \pm 0.07 vs Dev+ Ruth Red: $0.65 \pm 0.07, \mathrm{P}=0.22$ ) or P-CaMKII (Dev: $0.98 \pm 0.06$ vs Dev+Ruth Red: $0.87 \pm 0.08, P=0.53$, both NS). With FCCP (10 nM) Dev, $0.47 \pm 0.04$ vs Dev+FCCP $0.50 \pm 0.04$ for P-elF2a and Dev, $0.70 \pm$ 0.07 vs Dev+FCCP, $0.64 \pm 0.06$ for $\mathrm{P}-\mathrm{CaMKII}, \mathrm{P}=\mathrm{NS}$. Therefore, the mitochondria are unlikely to be the source of $\left[\mathrm{Ca}^{2+}\right]_{i}$ in this model.

Gene chip analysis: We updated and re-analyzed data obtained earlier from APC taken after feeding BAS or Dev diet for $2 \mathrm{hr}$, allowing time for transcription. Methods and portions of these data have been published in a report on GABA receptors [20]. Among 112 significantly altered transcripts, those associated with $\mathrm{Ca}^{2+}$ showed a $\mathrm{P}$ value of 0.007 ; those associated with intracellular trafficking (suggested to be involved by Gulati et al. [15]) were significant at $P=0.002$. CaN $A \beta$ (Ppp3cb, -2.0 fold), along with the $\beta$ subunit of CaMKII (Camk2b, -5.6), and the $\mathrm{Ca}^{2+}$-regulated $\mathrm{G} \beta$ protein, (RAS, Gnb1, [26] +8.6 and +5.4), were among the significant findings for $\mathrm{Ca}^{2+}$-associated transcripts.

\section{Discussion}

Taken together, biochemical (Western blot), electrophysiological (EPSP amplitude), and transcript-array results provide clear support for a $\mathrm{Ca}^{2+}$ requirement in regulating both the phosphorylation of elF2a and CaMKII, as well as the activation of the APC by IAA depletion. When we chelated $\left[\mathrm{Ca}^{2+}\right]_{i}$, blocked its entry into the cell, or blocked its release from the ER via ryanodine, these phospho-protein levels, or the EPSP, or both, were reduced. Moreover, consistent with these suggestions, $\mathrm{Ca}^{2+}$ related transcripts were significantly affected in APC tissue from Dev fed rats.

An important finding from this work is that the kinase 
activity of GCN2 did not depend on $\mathrm{Ca}^{2+}$, showing that the similarly reduced P-elF2a levels in both $\mathrm{BAP}+\mathrm{Cont}$ and $\mathrm{BAP}+\mathrm{Dev}$ conditions must be due to dephosphorylation. Because P-elF2a was reduced in the presence of BAP, we conclude that this reduction implicates $\mathrm{Ca}^{2+}$-dependent phosphatase activity. The phosphatase that acts selectively on elF2a phosphorylated by GCN2, is protein phosphatase 1 (PP1) with a regulatory (inhibitory) subunit, PPP1R15b, the constitutive repressor of elF2a phosphorylation (CReP) [27,28]. The constitutive feature of CReP is important, because the entire biochemical and behavioral sequence, including deficient diet rejection occurs in $20 \mathrm{~min}$. The two other regulatory subunits of PP1 are growth arrest and DNA damage-inducible protein/MyD116 (GADD34/ PPP1R15a) and the viral ICP34.5 [29]; both require about $2 \mathrm{hr}$ for activation [30]; such timing rules them out as the PP1 subunit in the present model.

The role of $\mathrm{Ca}^{2+}$ : A precedent for a $\left[\mathrm{Ca}^{2+}\right]_{i}$ effect on downstream components, including CaM [13] the RAS pathway [26] and calcineurin ( $\mathrm{CaN}$ ) is shown in brain ischemia [31]. CaN is dependent on CaM, which is clearly seen in layer II of the APC [32], reviewed in Sharp et al. [13]; CaM makes up $1 \%$ of total forebrain protein [33]. CaN (PP2B) is the only known protein serine/threonine phosphatase that is reported to be directly regulated by $\mathrm{Ca}^{2+} / \mathrm{CaM}$ [34]; importantly CaN is the only $\mathrm{Ca}^{2+}$-regulated phosphatase in brain [35]. $\mathrm{CaN}$ is found in both presynaptic [36] and postsynaptic [37] neurons and accounts for another $1 \%$ of total brain protein [38]. CaN has catalytic (A) and regulatory (B) subunits; in situ hybridization clearly shows high levels of both CaNAa and $\beta$ in the very cell body layer of APC that is involved in IAA sensing, see Figure $4 C$ in Takaishi et al. [32]. CaN also acts with PP1's regulatory subunits, which in the case of GCN2-phosphorylated elF2a would be CReP [28].

\section{Conclusions}

The role of the IAA-depletion/uncharged tRNA/ GCN2/P-elF2a pathway in the APC's responses to IAA depletion is established [10]. With P-elF2a blocking the initiation of protein synthesis, inhibitory features in the
APC circuit are lost and the APC is activated [11]. As prolonged activation of the APC can lead to seizures, restoration of protein synthesis via control of $\mathrm{P}$-elF2a is vital [39]. We suggest that PP1/CReP complexed with $\mathrm{Ca}^{2+} / \mathrm{CaM}$-dependent $\mathrm{CaN}$, participates in the regulation of P-elF2a in the APC. Moreover, this important regulator of elF2 phosphorylation, CReP, which is conserved in drosophila [28], has here been confirmed in the APC of the mammalian brain.

\section{Acknowledgements}

The authors thank Dr. Ron Wek for his thoughtful comments on an earlier version of the manuscript. This work was supported by: National Institutes of Health (NS33347, NS043210) and US Department of Agriculture (A 2000-01049). There are no conflicts of interest.

\section{Author Contributions}

CMR-I did the immunohistochemistry and analyzed the Western blot data; JBR and SH did the electrophysiology; JBR analyzed the EPSP data and prepared those figures. CMR-I and SH prepared the genechip materials. MD contributed to analysis of the genechip data. DWG did the statistical analysis, assembled the figures and prepared the final drafts. All the authors contributed to the study design and the writing and editing of the manuscript.

\section{References}

1. Leung PM, Rogers QR (1971) Importance of prepyriform cortex in food-intake response of rats to amino acids. Am J Physiol 221: 929-935.

2. Gietzen DW, Hao S, Anthony TG (2007) Mechanisms of food intake repression in indispensable amino acid deficiency. Annu Rev Nutr 27: 63-78.

3. Koehnle TJ, Russell MC, Gietzen DW (2003) Rats rapidly reject diets deficient in essential amino acids. J Nutr 133: 2331-2335. 
4. Hasan Z, Woolley D, Gietzen D (1998) Responses to indispensable amino acid deficiency and replenishment recorded in the anterior piriform cortex of the behaving rat. Nutr Neurosci 1: 373381.

5. Rudell JB, Rechs AJ, Kelman TJ, Ross-Inta $\mathrm{CM}$, Hao $S$, et al. (2011) The anterior piriform cortex is sufficient for detecting depletion of an indispensable amino acid, showing independent cortical sensory function. J Neurosci 31: 15831590.

6. Ekstrand JJ, Domroese ME, Johnson DM, Feig SL, Knodel SM, et al. (2001) A new subdivision of anterior piriform cortex and associated deep nucleus with novel features of interest for olfaction and epilepsy. J Comp Neurol 434: 289-307.

7. Sharp JW, Ross-Inta CM, Hao S, Rudell JB, Gietzen DW (2006) Co-localization of phosphorylated extracellular signal-regulated protein kinases $1 / 2$ (ERK1/2) and phosphorylated eukaryotic initiation factor 2alpha (elF2alpha) in response to a threonine-devoid diet. J Comp Neurol 494: 485-494.

8. Gietzen DW, Aja SM (2012) The brain's response to an essential amino acid-deficient diet and the circuitous route to a better meal. Mol Neurobiol 46: 332-348.

9. Hao S, Sharp JW, Ross-Inta CM, McDaniel BJ, Anthony TG, et al. (2005) Uncharged tRNA and sensing of amino acid deficiency in mammalian piriform cortex. Science 307: 1776-1778.

10. Anthony TG, Gietzen DW (2013) Detection of amino acid deprivation in the central nervous system. Curr Opin Clin Nutr Metab Care 16: 96101.

11. Sharp JW, Ross-Inta CM, Baccelli I, Payne JA, Rudell JB, et al. (2013) Effects of essential amino acid deficiency: Down-regulation of $\mathrm{KCC}$ and the $\mathrm{GABA}_{\mathrm{A}}$ receptor; disinhibition in the anterior piriform cortex. J Neurochem 127: 520-530.

12. Magrum LJ, Hickman MA, Gietzen DW (1999) Increased intracellular calcium in rat anterior piriform cortex in response to threonine after threonine deprivation. J Neurophysiol 81: 11471149.

13. Sharp JW, Ross CM, Koehnle TJ, Gietzen DW (2004) Phosphorylation of $\mathrm{Ca}^{2+} /$ calmodulindependent protein kinase type II and the alpha-amino-3-hydroxy-5-methyl-4-isoxazole propionate (AMPA) receptor in response to a threonine-devoid diet. Neuroscience 126: 10531062.

14. Conigrave AD, Quinn SJ, Brown EM (2000) L-amino acid sensing by the extracellular $\mathrm{Ca}^{2+}$ sensing receptor. Proc Natl Acad Sci U S A 97: 4814-4819.

15. Gulati P, Gaspers LD, Dann SG, Joaquin M, Nobukuni T, et al. (2008) Amino acids activate mTOR complex 1 via $\mathrm{Ca}^{2+} / \mathrm{CaM}$ signaling to hVps34. Cell Metab 7: 456-465.

16. Hao S, Ross-Inta CM, Gietzen DW (2010) The sensing of essential amino acid deficiency in the anterior piriform cortex, that requires the uncharged tRNA/GCN2 pathway, is sensitive to wortmannin but not rapamycin. Pharmacol Biochem Behav 94: 333-340.

17. Hou L, Klann E (2004) Activation of the phosphoinositide 3-kinase-Akt-mammalian target of rapamycin signaling pathway is required for metabotropic glutamate receptor-dependent long-term depression. J Neurosci 24: 6352-6361.

18. Munoz F, Martin ME, Salinas M, Fando JL (2001) Carbonyl cyanide p-trifluoromethoxyphenylhydrazone (FCCP) induces initiation factor 2 alpha phosphorylation and translation inhibition in pc12 cells. FEBS Lett 492: 156-159.

19. Hinnebusch AG (2005) Translational regulation of GCN4 and the general amino acid control of yeast. Annu Rev Microbiol 59: 407-450.

20. Truong BG, Magrum LJ, Gietzen DW (2002) $\operatorname{GABA}(\mathrm{A})$ and $\mathrm{GABA}(\mathrm{B})$ receptors in the anterior piriform cortex modulate feeding in rats. Brain Res Mol Brain Res 924: 1-9. 
21. Tsien RY (1980) New calcium indicators and buffers with high selectivity against magnesium and protons: Design, synthesis, and properties of prototype structures. Biochemistry 19: 23962404.

22. Kimball SR, Clemens MJ, Tilleray VJ, Wek RC, Horetsky RL, et al. (2001) The doublestranded RNA-activated protein kinase PKR is dispensable for regulation of translation initiation in response to either calcium mobilization from the endoplasmic reticulum or essential amino acid starvation. Biochem Biophys Res Commun 280: 293-300.

23. Verkhratsky A (2005) Physiology and pathophysiology of the calcium store in the endoplasmic reticulum of neurons. Physiol Rev 85: 201-279.

24. Klein RR, Bourdon DM, Costales CL, Wagner CD, White WL, et al. (2011) Direct activation of human phospholipase $\mathrm{C}$ by its well known inhibitor U73122. J Biol Chem 286: 12407-12416.

25. Taylor CW, Broad LM (1998) Pharmacological analysis of intracellular $\mathrm{Ca}^{2+}$ signalling: Problems and pitfalls. Trends Pharmacol Sci 19: 370-375.

26. Cullen PJ, Lockyer PJ (2002) Integration of calcium and RAS signalling. Nat Rev Mol Cell Biol 3: 339-348.

27. Jousse C, Oyadomari S, Novoa I, Lu P, Zhang Y, et al. (2003) Inhibition of a constitutive translation initiation factor 2alpha phosphatase, CReP, promotes survival of stressed cells. J Cell Biol 163: 767-775.

28. Malzer E, Szajewska-Skuta M, Dalton LE, Thomas $\mathrm{SE}, \mathrm{Hu} \mathrm{N}$, et al. (2013) Coordinate regulation of elF2alpha phosphorylation by PPP1R15 and GCN2 is required during drosophila development. J Cell Sci 126: 1406-1415.

29. Chou J, Roizman B (1994) Herpes simplex virus 1 gamma(1)34.5 gene function, which blocks the host response to infection, maps in the homologous domain of the genes expressed during growth arrest and DNA damage. Proc Natl
Acad Sci U S A 91: 5247-5251.

30. Doutheil J, Althausen S, Gissel C, Paschen W (1999) Activation of MYD116 (gadd34) expression following transient forebrain ischemia of rat: Implications for a role of disturbances of endoplasmic reticulum calcium homeostasis. Brain Res Mol Brain Res 63: 225-232.

31. White BC, Sullivan JM, DeGracia DJ, O'Neil BJ, Neumar RW, et al. (2000) Brain ischemia and reperfusion: Molecular mechanisms of neuronal injury. J Neurol Sci 179: 1-33.

32. Takaishi T, Saito N, Kuno T, Tanaka C (1991) Differential distribution of the mRNA encoding two isoforms of the catalytic subunit of calcineurin in the rat brain. Biochem Biophys Res Commun 174: 393-398.

33. Erondu NE, Kennedy MB (1985) Regional distribution of type II $\mathrm{Ca}^{2+} /$ calmodulin-dependent protein kinase in rat brain. $\mathrm{J}$ Neurosci 5: 32703277.

34. Li L, Stefan MI, Le Novere N (2012) Calcium input frequency, duration and amplitude differentially modulate the relative activation of calcineurin and CaMKII. PLoS One 7: e43810.

35. Baumgartel K, Mansuy IM (2012) Neural functions of calcineurin in synaptic plasticity and memory. Learn Mem 19: 375-384.

36. Victor RG, Thomas GD, Marban E, O'Rourke B (1995) Presynaptic modulation of cortical synaptic activity by calcineurin. Proc Natl Acad Sci U S A 92: 6269-6273.

37. Wang JH, Kelly PT (1997) Postsynaptic calcineurin activity downregulates synaptic transmission by weakening intracellular $\mathrm{Ca}^{2+}$ signaling mechanisms in hippocampal CA1 neurons. J Neurosci 17: 4600-4611.

38. Kennedy MB (1992) Second messengers and neuronal function. In: Hall ZW (ed) An introduction to molecular neurobiology. Sinauer Assoc., Sunderland, Mass. 207-246.

39. Young SK, Willy JA, Wu C, Sachs MS, Wek 
RC (2015) Ribosome reinitiation directs genespecific translation and regulates the integrated stress response. J Biol Chem 290: 28257-28271.

Copyright: $\odot$ Gietzen et al. This is an Open Access article distributed under the terms of the Creative Commons Attribution License, which permits unrestricted use, distribution, and reproduction in any medium, provided the original work is properly cited. 